\title{
Permeability Evolution and Particle Size Distribution of Saturated Crushed Sandstone under Compression
}

\author{
Yanlong Chen $\mathbb{D})^{1,2}$ Bangyong Yu $\mathbb{D},{ }^{3}$ Kai Zhang $\mathbb{D}^{1,2}$ Mingwei Zhang $\mathbb{D}{ }^{1}$ \\ Guang Xu $\oplus^{4},{ }^{4}$ and Zhanqing Chen $\left(\mathbb{1}^{1}\right.$ \\ ${ }^{1}$ State Key Laboratory for Geomechanics and Deep Underground Engineering, China University of Mining \& Technology, \\ Xuzhou 221116, China \\ ${ }^{2}$ School of Mechanics and Civil Engineering, China University of Mining \& Technology, Xuzhou 221116, China \\ ${ }^{3}$ Institute of Construction Engineering Technology, Changzhou Vocational Institute of Engineering, Changzhou 213164, China \\ ${ }^{4}$ Department of Mining Engineering \& Metallurgical Engineering, Western Australian School of Mines, Curtin University, \\ Kalgoorlie, WA 6430, Australia \\ Correspondence should be addressed to Bangyong Yu; yby_cumt@126.com
}

Received 20 June 2017; Revised 20 October 2017; Accepted 21 November 2017; Published 10 January 2018

Academic Editor: Qinghui Jiang

Copyright (C) 2018 Yanlong Chen et al. This is an open access article distributed under the Creative Commons Attribution License, which permits unrestricted use, distribution, and reproduction in any medium, provided the original work is properly cited.

In this research, the particle size distribution and permeability of saturated crushed sandstone under variable axial stresses $(0,2,4$, 8,12 , and $16 \mathrm{MPa}$ ) were studied. X-ray Computed Tomography results revealed that particle crushing is likely to occur considerably as the axial stress is approaching $4 \mathrm{MPa}$, which results in the change of pore structure greatly. During compression, the particle size distribution satisfies the fractal condition well, and the fractal dimension of particle size distribution is an effective method for describing the particle crushing state of saturated crushed sandstone. When the axial stress increases from $0 \mathrm{MPa}$ to $4 \mathrm{MPa}$, the fractal dimension of the particle size distribution increases rapidly by over $60 \%$ of the total increase $(0-16 \mathrm{MPa})$, and the permeability decreases sharply by about $85 \%$ of the total decrease. These results indicate that $4 \mathrm{MPa}$ is a key value in controlling the particle size distribution and the permeability of the saturated crushed sandstone under axial compression. The permeability is influenced by the initial gradation of the specimens, and a larger Talbot exponent corresponds to a larger permeability.

\section{Introduction}

Due to the large permeability of crushed rocks, flow catastrophes and water inrush accidents can be easily triggered in the discontinuous zones of aquifers in underground coal mines $[1,2]$. The permeability of crushed rock is determined by the pore structure, which has a close relationship with the particle size distribution [3]. In recent decades, many related studies have been conducted to investigate the factors that affect the particle size distribution of granular materials [4-9]. The results show that particle size distribution is mainly affected by the applied stress, particle size, particle mixture, and other environmental factors (e.g., temperature and humidity of the environment).

Generally, two approaches that are fragmentation degree of the particle and fractal dimension are commonly adopted to describe the particle size distribution. Miura and O-Hara [10] and Hardin [11] proposed that the fragmentation degree of the particle might be useful indicator for quantitative analysis of the particle breakage of granular materials. In addition, Mandelbrot [12], Turcotte [13] and Xie and Pariseau [14] proposed the fractal theory and thought the calculated parameters of particle size distribution are more easily to be assessed via fractal theory. Furthermore, fractal theory is a powerful tool used to characterize phenomena that exhibit large, scaleinvariant, and self-similar characteristics [15-19]. It has been widely used in geotechnical engineering to describe the evolution of particle size distribution, especially in soils [15, 16, 20-22]. However, little research has been performed in the fractal analysis of the particle size distribution of crushed rocks (especially crushed rocks in caved zones in coal mining engineering). 
Lomoze first put forward a parallel-plates model to simulate the fluid flow in fractures [23]. Since then, many experiments on the water flow in fractured rocks had been carried out [1-3, 24-28]. Specifically, Miao et al. [1] analyzed the seepage properties of broken sandstone with different porosities; Ma et al. [2, 3] obtained the relationship between the permeability and variable grain diameters under variable axial displacements. They also investigated the effect of particle size mixture on the seepage properties and compaction behaviors of crushed mudstones. These studies show that the seepage properties of the fractured rocks are mainly affected by rock type, porosity, permeability, and other factors. However, these previous studies did not take into account the quantitative relationships among the particle size distribution, the porosity, and the permeability. In fact, these factors are constantly changing during the compression process, which have big influences on rock seepage properties.

Therefore, the studies of particle size distribution and permeability of crushed rocks play an important role in helping engineers understand how to assess the risk of water inrush. In this study, the saturated crushed sandstone was chosen to research the effect of the increase in axial loading on the variations of particle crushing, fractal dimension of particle size distribution, porosity, and permeability. Moreover, the quantitative relationships between fractal dimension and porosity and permeability are given. The results can provide a scientific basis for the prevention of water inrush accidents in coal mining.

\section{Experimental Materials and Testing Methods}

2.1. Experimental Materials. The sandstone specimens used in the test were collected from the $-560 \mathrm{~m}$ deep strata of the coal mine in China. By experimental analysis, the main mineral composition of the tested sandstone is $29 \%$ albite, 23\% quartz, 15\% calcite, 13\% laumontite, 9\% kaolinite, $7 \%$ illite, and $4 \%$ other minerals. The average dry density is $2450 \mathrm{~kg} / \mathrm{m}^{3}$. The uniaxial compressive strength, tensile strength, cohesion, and internal friction angle are $67.4 \mathrm{MPa}$, 8.3 $\mathrm{MPa}, 12.5 \mathrm{MPa}$, and $33.2^{\circ}$, respectively. In the above measurements, the rocks were processed into cylindrical specimens, which were $50 \mathrm{~mm}$ in diameter and $100 \mathrm{~mm}$ in length in the triaxial experiments with a loading rate of $1.0 \mathrm{kN} / \mathrm{s}$, and $50 \mathrm{~mm}$ in diameter and $25 \mathrm{~mm}$ in length in the Brazilian tests with a loading rate of $0.05 \mathrm{kN} / \mathrm{s}$.

First, the sandstone blocks were crushed, and then they were separated into different diameter sizes using separation screens. The particles in each specimen consisted of five diameter ranges: (a) $(2.5-5 \mathrm{~mm})$, (b) $(5-8 \mathrm{~mm}),(\mathrm{c})$ (8-10 mm), (d) (10-12 mm), and (e) (12-15 mm), as shown in Figure 1. In order to study the influence of the initial gradation of the specimens on the permeability, the sandstone particles within the different diameter ranges were proportioned according to the Talbot formula [29]:

$$
P_{i}=\left(\frac{d_{i}}{d_{M}}\right)^{n} \times 100 \%,
$$

where $d_{i}$ is the particle size, $d_{M}$ is the maximum size of the sandstone particles, $P_{i}$ is the mass percent of the sandstone particles in the specimen whose size is less than $d_{i}$, and $n$ is the Talbot exponent.

In the present test, the Talbot exponents were 0.2, 0.4, 0.6 , and 0.8 , and the total mass was $1500 \mathrm{~g}$. Table 1 shows the details of the mass of the sandstone particles in each diameter range for each specimen. As listed in Table 1, the mass amount of the larger particles increases with the increase of the Talbot exponent. Finally, the crushed specimens were placed into a glass container that filled with water for seven days to ensure that they were fully saturated.

2.2. Testing System. MTS 815.02 system and a self-designed seepage apparatus are the two major parts of the testing system, as shown in Figure 2. The loading indenter (1) was used to provide the axial loading. The O-shape rubber seal rings (2) were used to close the gap. The piston (3) was used to compress the rock specimen (7). The felt filtration pad (4) was used to prevent the testing system from being polluted by the fluid, and the porous plate (5) was used to ensure that the water flowed evenly. The saturated crushed sandstone was placed into the cylindrical tube (6), of which the inner diameter and wall thickness were 100 and $21 \mathrm{~mm}$, respectively.

2.3. Testing Procedure. In order to obtain the particle size distribution of the saturated crushed sandstone under different axial stresses, an axial force control mode was applied and the specimens were separated after the seepage test. Figure 3 illustrates the testing procedure.

Because of the movement of the overlying strata, the crushed rocks in the caved zones support different amounts of loading at different times. The resulting compression increases gradually due to the change of ground stress. Therefore, the impact of the compression level (axial stress) on particle size distribution and permeability should be investigated. Considering the strata depth $(-560 \mathrm{~m})$ and the in situ strata stress (average bulk density of $0.024 \mathrm{MN} / \mathrm{m}^{3}$ ), a maximum axial stress of $16 \mathrm{MPa}$ was set for the compression test. The axial stress was set to five different levels $(2,4,8,12$, and $16 \mathrm{MPa}$ ). Therefore, the particle size distribution and permeability can be tested under six different conditions (including the nonloading condition). Twenty-four sets of experiments were conducted (four initial gradations $\times$ six different axial stresses). Each set of experiments was carried out three times, and the average values of the test data were used for the analysis.

\section{Calculation of Fractal Dimension and Permeability}

3.1. Fractal Dimension of Particle Size Distribution. The definition of a fractal can be given based on the relationship between the number and feature scale in a statistically selfsimilar system $[12,13]$ and is given by the following equation:

$$
N(x>d)=C d^{-D}
$$




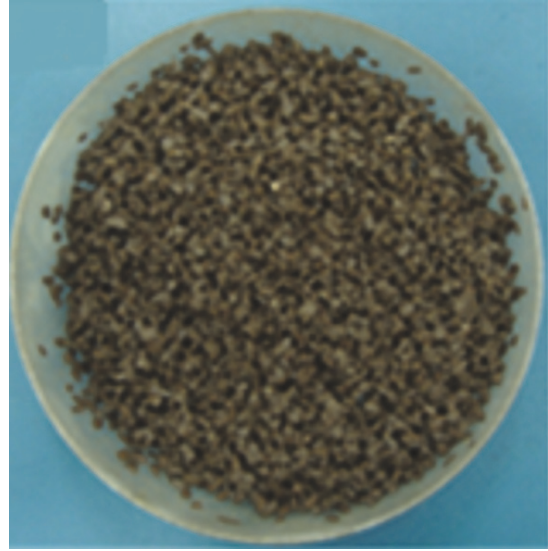

(a) $2.5-5 \mathrm{~mm}$

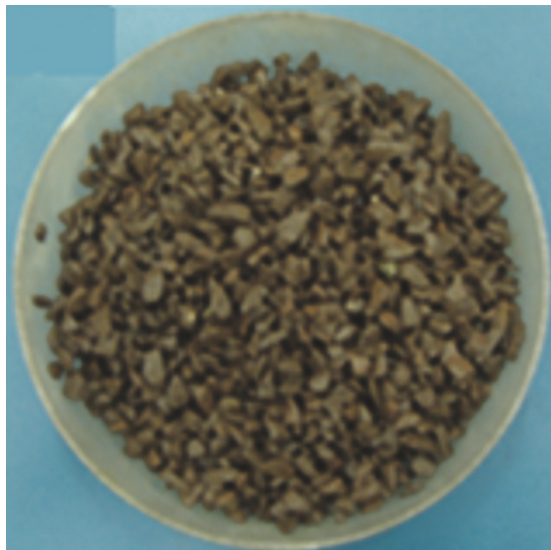

(b) $5-8 \mathrm{~mm}$

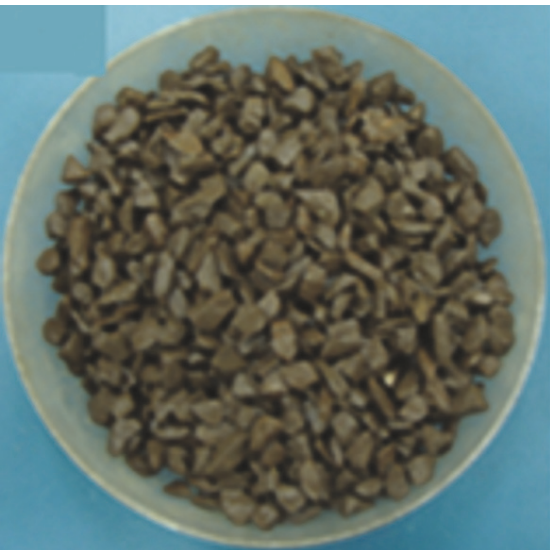

(c) $8-10 \mathrm{~mm}$

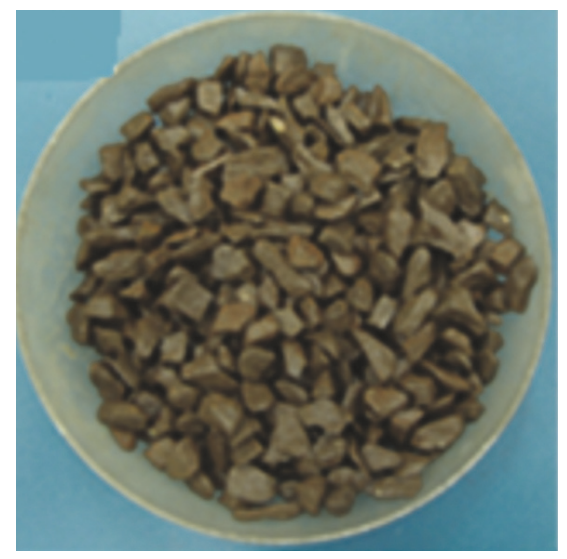

(d) $10-12 \mathrm{~mm}$

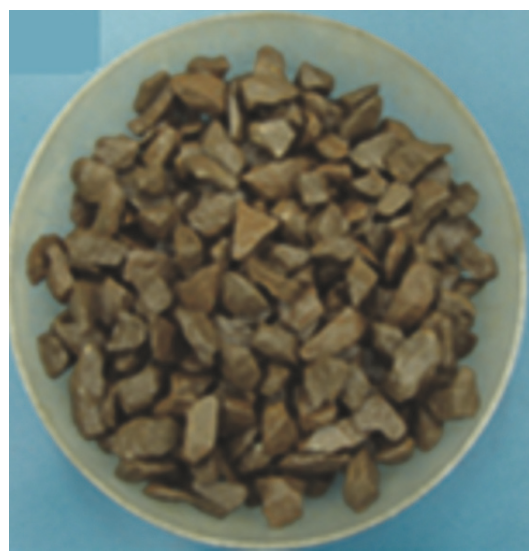

(e) $12-15 \mathrm{~mm}$

FIGURE 1: Five diameter ranges of crushed sandstone particles.

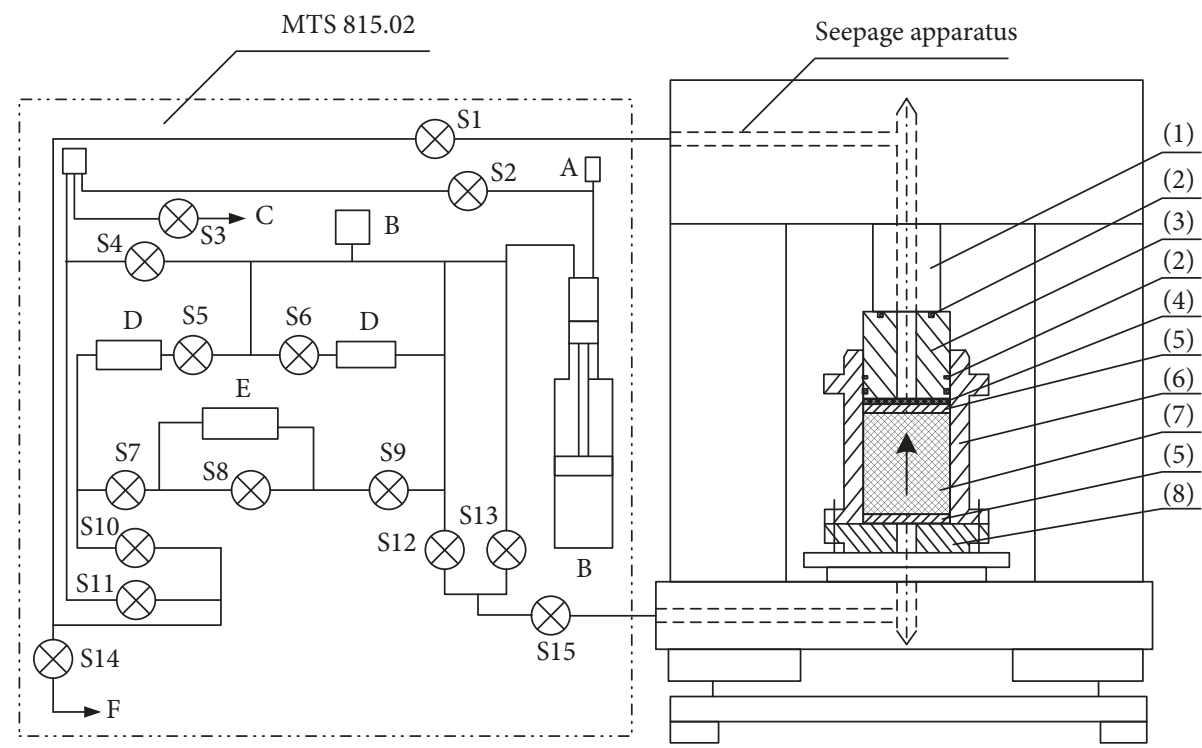

FIGURE 2: Testing system. Note: A: pressure sensor, B: relief valve, C: drainage, D: regulator, E: pressure difference sensor, F: load controller, S1 to S15 are switches, (1) loading indenter, (2) O-shape rubber seal rings, (3) piston, (4) felt filtration pad, (5) porous plate, (6) cylindrical tube, (7) rock specimen, and (8) base plate. 
TABLE 1: The details of the mass amount of the sandstone particles in each diameter range.

\begin{tabular}{|c|c|c|c|c|c|c|}
\hline \multirow{2}{*}{ Specimen number } & \multirow{2}{*}{ Talbot exponent $(n)$} & \multicolumn{5}{|c|}{ Mass in each diameter range (g) } \\
\hline & & $2.5-5 \mathrm{~mm}$ & $5-8 \mathrm{~mm}$ & $8-10 \mathrm{~mm}$ & $10-12 \mathrm{~mm}$ & $12-15 \mathrm{~mm}$ \\
\hline (1) & 0.2 & 517.5 & 394.1 & 200.4 & 170.6 & 217.4 \\
\hline (2) & 0.4 & 457.5 & 390.8 & 212.9 & 188.6 & 250.2 \\
\hline (3) & 0.6 & 400.8 & 383.7 & 223.7 & 206.4 & 285.4 \\
\hline (4) & 0.8 & 348.2 & 373.3 & 232.8 & 223.6 & 322.1 \\
\hline
\end{tabular}

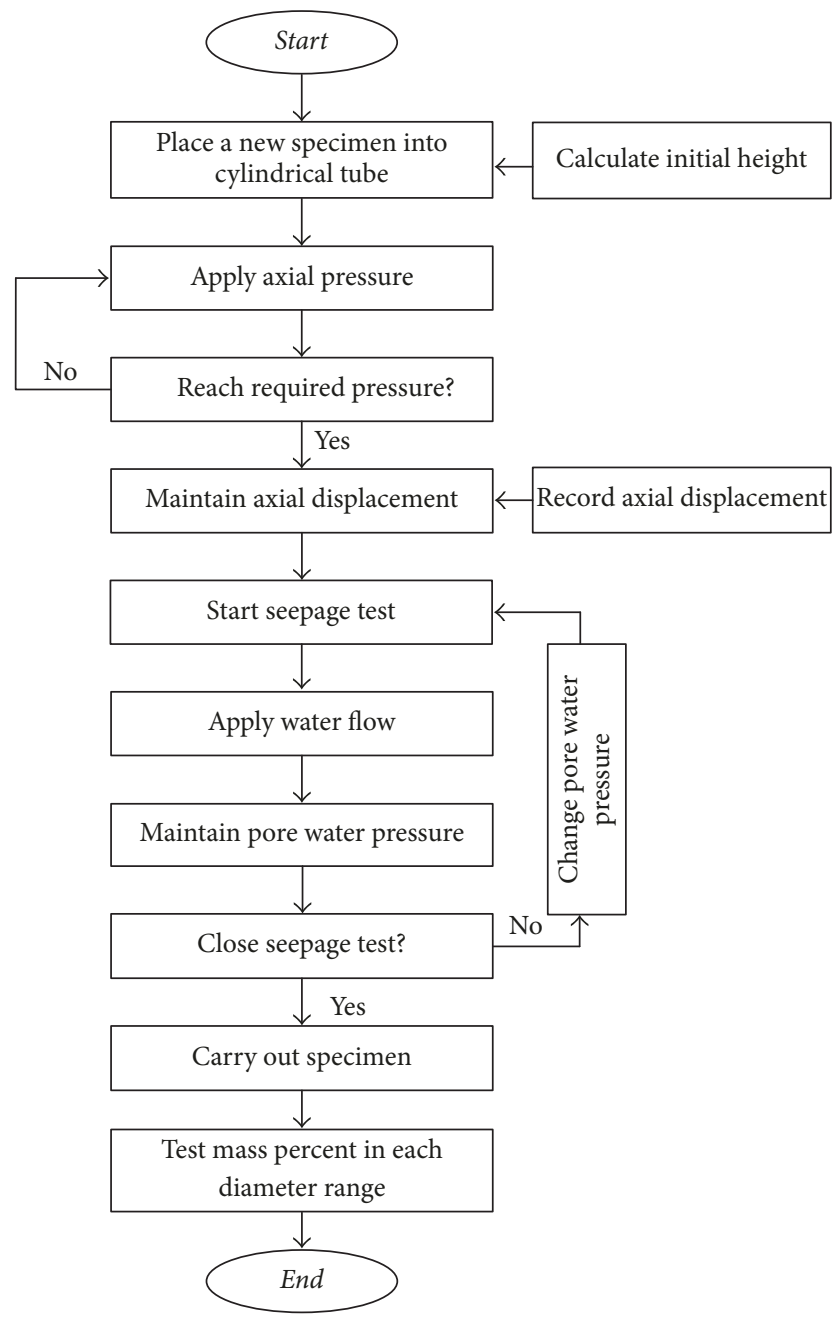

FIGURE 3: Testing procedure.

where $d$ is the feature scale of the rock particles, $N$ is the number of rock particles larger than $d, C$ is the proportionality coefficient, and $D$ is the fractal dimension of the particle size distribution.

However, the applicability of (2) for particle size distribution analysis is limited because the accurate calculations of $N$ values are typically unavailable from conventional particle size distribution experimental data. In order to compensate for the lack of $N$ values, Tyler and Wheatcraft [30] estimated the fractal dimension of the particle size distribution based on the following expression:

$$
\frac{M_{d}(x<d)}{M_{T}}=\left(\frac{d}{d_{M}}\right)^{3-D},
$$

where $M_{d}$ is the mass of the sandstone particles smaller than $d, M_{T}$ is the total mass of the specimen, and $d_{M}$ is the maximum diameter of the sandstone particles.

From (3), it is found that the relationship between $\lg \left(M_{d} / M_{T}\right)$ and $\lg \left(d / d_{M}\right)$ is linear, and the slope is $3-D$. As previously suggested, if the particle size distribution of the saturated crushed sandstone in the compression test can satisfy the fractal condition, we can fit the straight line of $\lg \left(M_{d} / M_{T}\right)-\lg \left(d / d_{M}\right)$ to obtain the fractal dimension of the particle size distribution.

3.2. Permeability Calculation. The Forchheimer equation [31] can be used to describe the relationship between the water pressure gradient and the flow velocity in crushed rocks $[1,3]$. For a one-dimensional non-Darcy flow, the relationship can be expressed as

$$
\frac{-\partial p}{\partial z}=\mu_{0} k^{-1} v+\rho_{l} \beta v^{2},
$$

where $\partial p / \partial z$ is the pore water pressure gradient, $p$ is the pore water pressure, $z$ is the vertical axis going through the center of the specimen, $\mu_{0}$ is the kinetic viscosity of the water, $k$ is the permeability, $v$ is the water flow velocity, $\rho_{l}$ is the water density, and $\beta$ is the non-Darcy coefficient.

As shown in Figure 2, the upstream end of the specimen is connected to the pressure intensifier tank in the MTS 815.02 system. Such a connection could apply the required pore water pressure $p_{1}$. The downstream end of the specimen is connected to the atmosphere; thus the pore water pressure $p_{2}$ is equal to zero.

If all parameters on the right side of (4) do not change with $z$, then the pore water pressure gradient $\partial p / \partial z$ is a constant, which can be calculated using

$$
\frac{\partial p}{\partial z}=\frac{\left(p_{2}-p_{1}\right)}{H}=\frac{-p_{1}}{H},
$$

where $H$ is the specimen height. Therefore, (4) can be expressed as

$$
\frac{p_{1}}{H}=\mu_{0} k^{-1} v+\rho_{l} \beta v^{2} .
$$




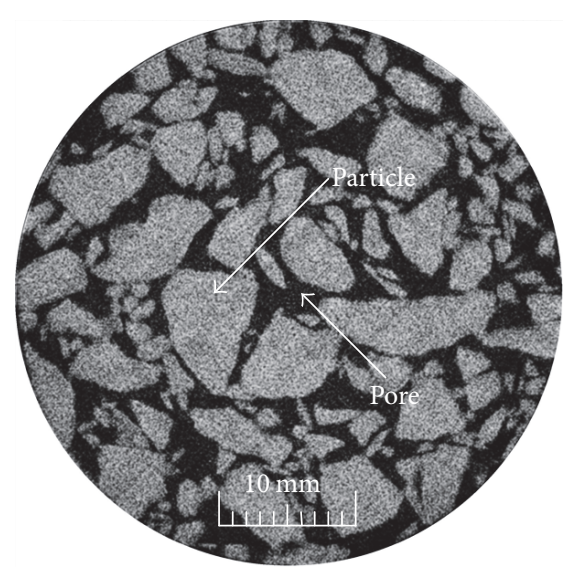

(a) $0 \mathrm{MPa}$

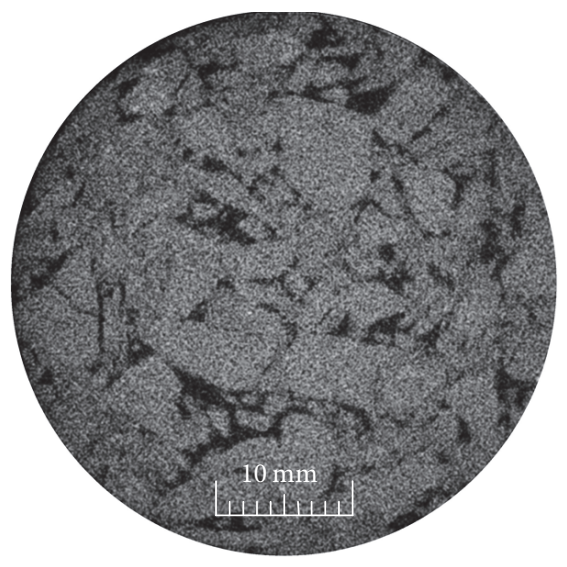

(d) $8 \mathrm{MPa}$

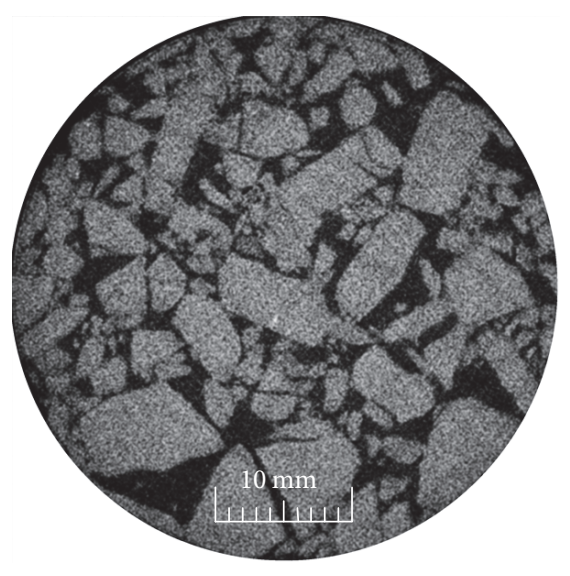

(b) $2 \mathrm{MPa}$

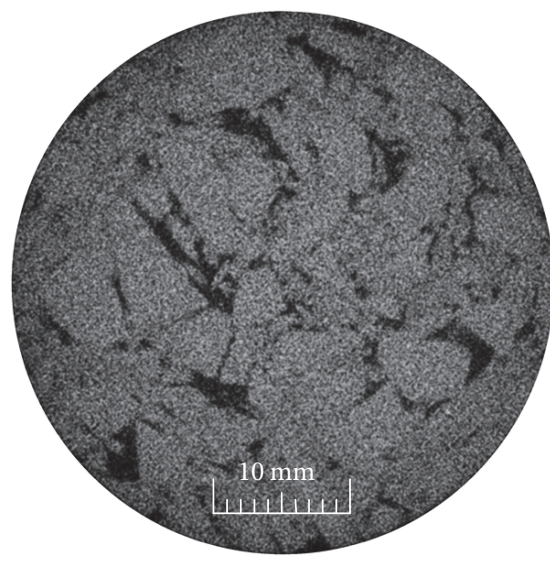

(e) $12 \mathrm{MPa}$

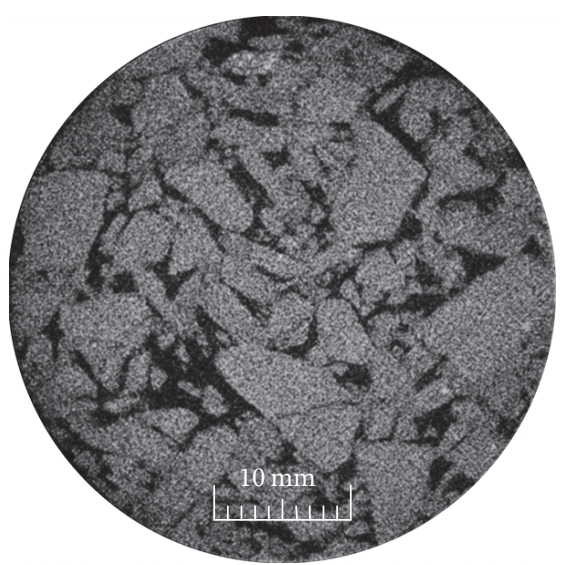

(c) $4 \mathrm{MPa}$

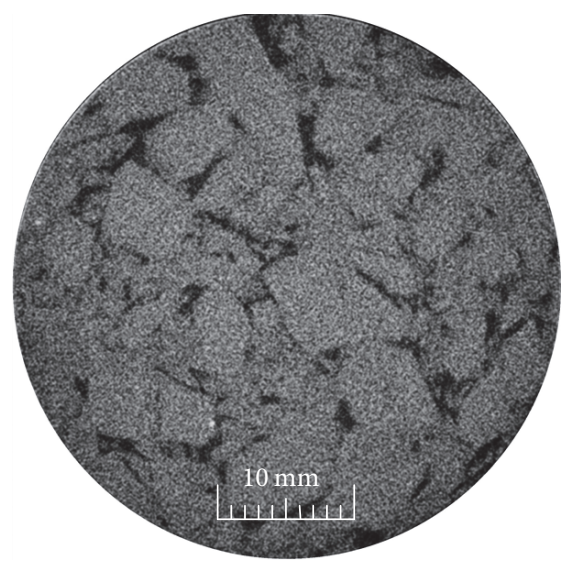

(f) $16 \mathrm{MPa}$

FIGURE 4: The formed process of isolated pores in the specimen under the increased axial stresses.

In the above described test, we could obtain the steady water flow velocity corresponding to each required pore water pressure. Based on (6), the permeability of the saturated crushed sandstone could be obtained by fitting the $p_{1}-v$ curves.

\section{Results and Discussion}

4.1. Micromechanism for Pore Structure Evolution. Figure 4 shows the X-ray CT images of the specimens with $n=0.8$ under different axial stresses. At the initial state $(0 \mathrm{MPa})$, as shown in Figure 4(a), the sample was very loose due to a few contact points between the particles and the large pore size. The particles accumulated together in a disordered way and made contact with each other in the modes of point-to-point and point-to-surface. In addition, the pore connectivity was quite good, and there were few isolated pores. After loading was applied, many secondary particles appeared, indicating the occurrence of particle crushing. Particles were moved and rearranged, and the mode of contact was gradually transformed to surface-to-surface contact, which is relatively stable. In particular, when the axial stress was increased, the number and size of pores decreased greatly, and the connectivity between pores became poor. Under the higher axial stress, as shown in Figure 4(f), most of the pores were compressed or filled with small particles. The residual pores were isolated, and the pore shape evolved from an unstable polygon into a stable triangle. Moreover, during the compression, larger pores were mainly distributed around larger particles, indicating that larger particles are more likely to cause larger capillary tubes for water flow.

4.2. Fractal Dimension of Particle Size Distribution. Based on the mass percent of the rock particles in each diameter range under variable axial stresses, we can calculate the corresponding fractal dimension of the particle size distribution. Saturated crushed sandstone specimens of $n=0.8$ will be described as an example to show how the fractal dimension was calculated. First, we obtained the mass percent of the rock particles in each diameter range under different axial stresses, as shown in Table 2. Next, from Table 2, we calculated the values of $\lg \left(M_{d} / M_{T}\right)$ and $\lg \left(d / d_{M}\right)$. Finally, according to (3), we fit the straight lines of $\lg \left(M_{d} / M_{T}\right)-\lg \left(d / d_{M}\right)$ and calculate the fractal dimension, as shown in Figure 5. In Figure 5, it can be seen that the particle size distribution of the saturated crushed sandstone satisfies the fractal condition 
TABLE 2: The mass percent of the rock particles in each diameter range of the saturated crushed sandstone with $n=0.8$ under variable axial stresses.

\begin{tabular}{|c|c|c|c|c|c|c|}
\hline \multirow{2}{*}{ Axial stress $(\mathrm{MPa})$} & \multicolumn{6}{|c|}{ Mass percent in each diameter range (\%) } \\
\hline & $0-2.5 \mathrm{~mm}$ & $2.5-5 \mathrm{~mm}$ & $5-8 \mathrm{~mm}$ & $8-10 \mathrm{~mm}$ & $10-12 \mathrm{~mm}$ & $12-15 \mathrm{~mm}$ \\
\hline 0 & 0 & 23.21 & 24.89 & 15.52 & 14.91 & 21.47 \\
\hline 2 & 15.94 & 16.34 & 25.35 & 12.67 & 14.03 & 15.67 \\
\hline 4 & 21.23 & 15.03 & 28.40 & 13.20 & 10.70 & 11.44 \\
\hline 8 & 27.88 & 13.45 & 26.71 & 10.63 & 11.68 & 9.65 \\
\hline 12 & 30.87 & 15.25 & 23.29 & 11.17 & 10.62 & 8.81 \\
\hline 16 & 33.71 & 12.44 & 26.37 & 10.09 & 9.65 & 7.75 \\
\hline
\end{tabular}

TABLE 3: Fractal dimension of the particle size distribution under variable axial stresses.

\begin{tabular}{|c|c|c|c|c|c|c|c|}
\hline \multirow{2}{*}{ Specimen number } & \multirow{2}{*}{ Talbot exponent $(n)$} & \multicolumn{6}{|c|}{ Fractal dimension $(D)$ under variable axial stresses } \\
\hline & & $0 \mathrm{MPa}$ & $2 \mathrm{MPa}$ & $4 \mathrm{MPa}$ & $8 \mathrm{MPa}$ & $12 \mathrm{MPa}$ & $16 \mathrm{MPa}$ \\
\hline (1) & 0.2 & 2.098 & 2.242 & 2.339 & 2.403 & 2.458 & 2.491 \\
\hline (2) & 0.4 & 1.985 & 2.177 & 2.289 & 2.363 & 2.442 & 2.459 \\
\hline (3) & 0.6 & 1.863 & 2.081 & 2.243 & 2.328 & 2.375 & 2.406 \\
\hline (4) & 0.8 & 1.733 & 1.993 & 2.146 & 2.280 & 2.345 & 2.384 \\
\hline
\end{tabular}

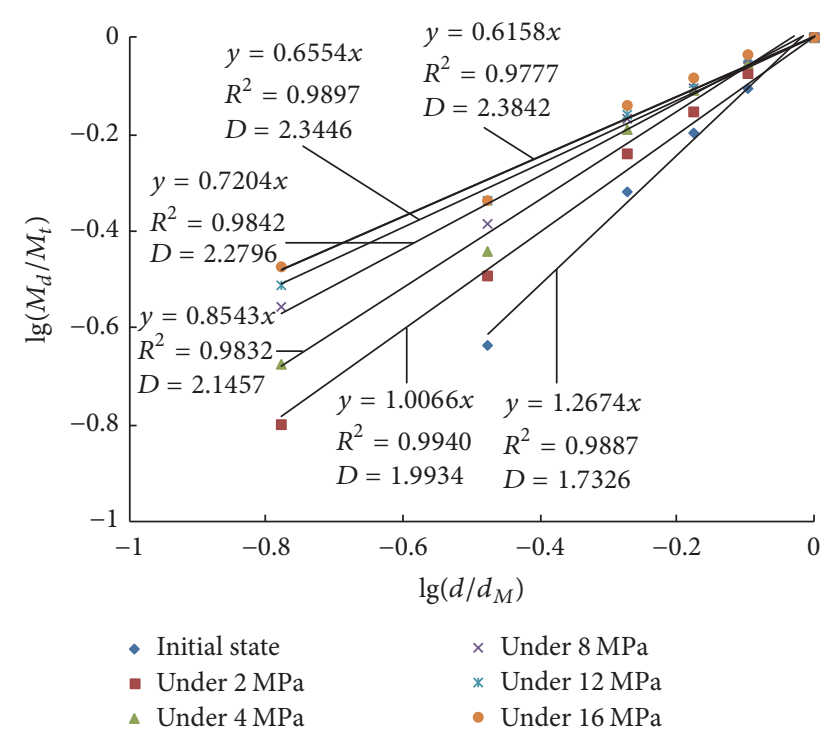

FIGURE 5: Fitting process curves of the fractal dimension with $n=$ 0.8 .

well, and all of the correlation coefficients are in the range of 0.9777 to 0.9940 . Moreover, the fractal dimension increases monotonically with an increase in the mass percent of small particles, and there is a one-to-one correspondence between a fractal dimension value and the particle size distribution. Thus, it can be concluded that the fractal dimension of the particle size distribution is an effective parameter to describe the particle crushing state of the saturated crushed sandstone.

Table 3 shows the calculated fractal dimension, and Figure 6 shows the fractal dimension-axial stress curves. In Figure 6, it can be seen that the fractal dimension that ranges from 1.733 to 2.491 increases with an increase in the

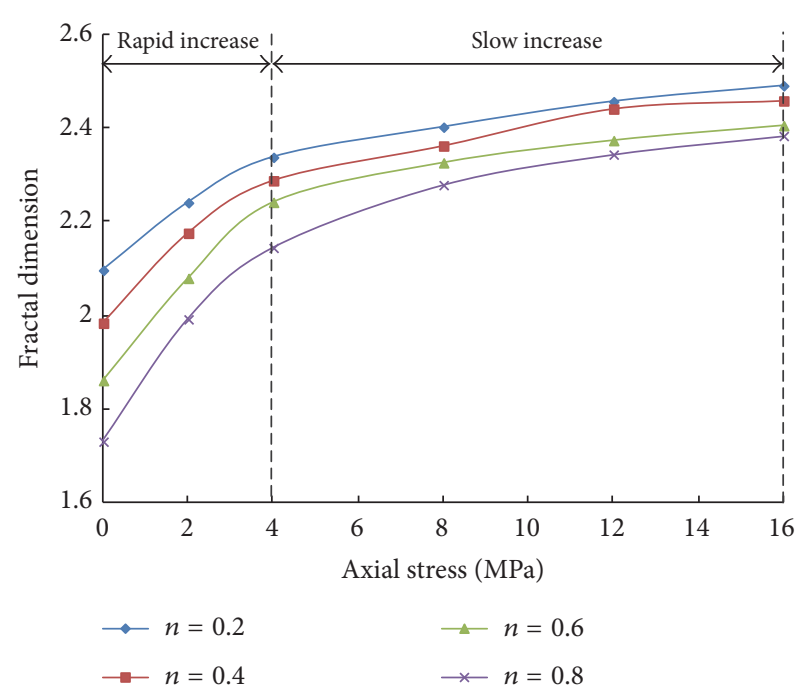

FIgURE 6: The increase process of the fractal dimension with the axial stress.

axial stress. The increase process consists of two stages that are a rapid increase $(0-4 \mathrm{MPa})$ stage and a slow increase (4-16 MPa) stage. During the rapid increase stage, the fractal dimension of the particle size distribution increases rapidly by over $60 \%$ of the total increase $(0-16 \mathrm{MPa})$. This is mainly due to the fact that there are a large number of large particles during the early stage of the compaction. There exist many flaws, harp corners, and the unstable contact modes between particles (including point-to-point and point-to-surface), which result in the concentration of stress. As a result, a large amount of particle crushing occurs (see Figure 4) and the fractal dimension increases rapidly. In comparison, the number of large particles decreases during the later stage. 
TABLE 4: Porosity under variable axial stresses.

\begin{tabular}{lcccccc}
\hline \multirow{2}{*}{ Specimen number } & \multirow{2}{*}{ Talbot exponent $(n)$} & \multicolumn{4}{c}{ Porosity $(\varphi)$ under variable axial stresses } \\
& & $0 \mathrm{MPa}$ & $2 \mathrm{MPa}$ & $4 \mathrm{MPa}$ & $8 \mathrm{MPa}$ & $12 \mathrm{MPa}$ \\
\hline$(1)$ & 0.2 & 0.415 & 0.309 & 0.247 & 0.195 & 0.167 \\
$(2)$ & 0.4 & 0.422 & 0.317 & 0.254 & 0.201 & 0.173 \\
$(3)$ & 0.6 & 0.432 & 0.326 & 0.262 & 0.206 & 0.179 \\
$(4)$ & 0.8 & 0.449 & 0.346 & 0.284 & 0.217 & 0.152 \\
\hline
\end{tabular}

TABLE 5: The values of those measured parameters to calculate porosity.

\begin{tabular}{lccccccccc}
\hline $\begin{array}{l}\text { Specimen } \\
\text { number }\end{array}$ & $m(\mathrm{~g})$ & $\rho_{s}\left(\mathrm{~kg} / \mathrm{m}^{3}\right)$ & $\mathrm{Q}\left(\mathrm{mm}^{2}\right)$ & $n$ & \multicolumn{4}{c}{ Specimen height $(h)$ under variable axial stresses $(\mathrm{mm})$} \\
\hline$(1)$ & 1541 & 2518 & 7850 & 0.2 & 133.3 & 112.9 & 103.5 & 96.8 & 93.6 \\
$(2)$ & 1541 & 2518 & 7850 & 0.4 & 134.9 & 114.1 & 104.5 & 97.6 & 94.2 \\
$(3)$ & 1541 & 2518 & 7850 & 0.6 & 137.3 & 115.7 & 105.6 & 98.2 & 91.9 \\
$(4)$ & 1541 & 2518 & 7850 & 0.8 & 141.6 & 119.2 & 108.9 & 99.5 & 96.0 \\
\hline
\end{tabular}

The particle shapes are relatively regular, and the contacts between particles are relatively stable. Therefore, only a slight amount of particle crushing occurs and the fractal dimension increases slowly.

4.3. Porosity. The porosity of the saturated crushed sandstone is a measurement of the fraction of void spaces in the specimen, which can be expressed as

$$
\varphi=1-\frac{m}{\rho_{s} Q h},
$$

where $\varphi, m, \rho_{s}, h$, and $Q$ are the porosity, mass, mass density, the height of the specimen during compaction, and the crosssectional area of the cylindrical tube, respectively.

Table 4 shows the calculated porosity, and the values of those measured parameters to calculate the porosity are listed in Table 5. Figure 7 shows the porosity-fractal dimension curves. In Figure 7, it can be seen that the porosity decreases with an increase in the fractal dimension of the particle size distribution. That is mainly due to the fact that a larger fractal dimension corresponds to a larger mass percent of small particles. This will accelerate particle rearrangement and fill in the pores between large particles (see Figure 4), resulting in a decrease in the porosity. Moreover, the relation between the porosity and the fractal dimension can be described by a linear function:

$$
\varphi=a_{1} D+b_{1},
$$

where $\varphi$ is the porosity, $D$ is the fractal dimension of the particle size distribution, and $a_{1}$ and $b_{1}$ are the regression coefficients.

4.4. Permeability. Table 6 shows the calculated permeability, and the values of parameters used to calculate the permeability are listed in Table 7 . Figure 8 shows the permeability-axial stress curves. In Figure 8, it can be seen that the permeability that ranges from $3.48 \times 10^{-14}$ to $67.16 \times 10^{-14} \mathrm{~m}^{2}$ decreases

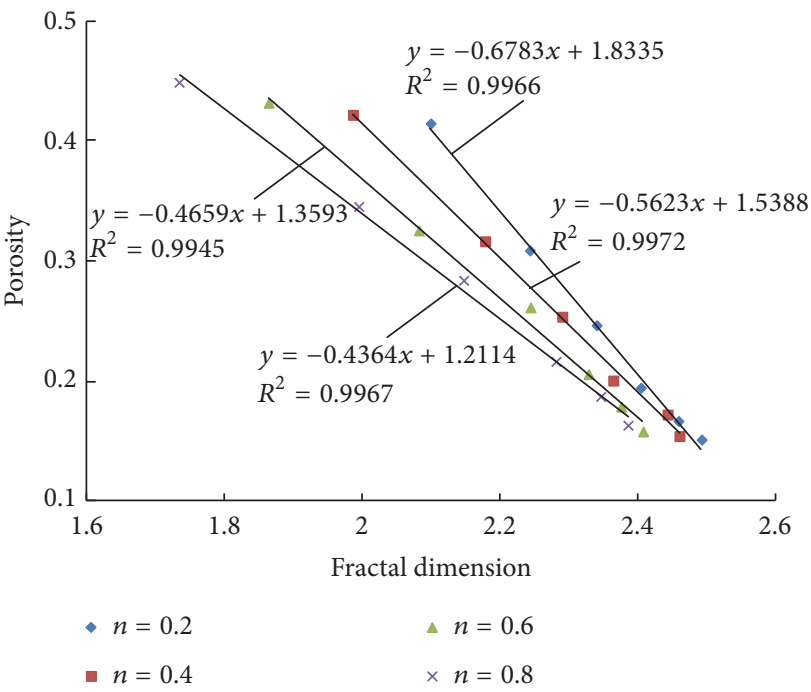

FIGURE 7: The linear decline curves between the porosity and the fractal dimension.

with an increase in the axial stress. The decrease process can be divided into two stages which correspond to the two stages of the fractal dimension of the particle size distribution. In the initial state, as presented in the X-ray CT results (see Figure 4), the pore size is large and the pore connectivity is quite good. As a result, the permeability is large. In the rapid increase stage of the fractal dimension $(0-4 \mathrm{MPa})$, a large amount of small particles occurs and fills in the pores between large particles. Many pores are compressed greatly and closed, and the pore connectivity becomes poor. Therefore, the permeability decreases sharply by about $85 \%$ of the total decrease $(0-16 \mathrm{MPa})$. In the slow increase stage (4-16 MPa), a slight amount of particle crushing occurs due to the good contacts between the particles. The pore size and pore connectivity change slightly, and thus the permeability decreases slowly. In addition, the pore structure becomes 
TABLE 6: Permeability under variable axial stresses.

\begin{tabular}{|c|c|c|c|c|c|c|c|}
\hline \multirow{2}{*}{ Specimen number } & \multirow{2}{*}{ Talbot exponent $(n)$} & \multicolumn{6}{|c|}{ Permeability $(k)$ under variable axial stresses $\left(10^{-14} \mathrm{~m}^{2}\right)$} \\
\hline & & $0 \mathrm{MPa}$ & $2 \mathrm{MPa}$ & $4 \mathrm{MPa}$ & $8 \mathrm{MPa}$ & $12 \mathrm{MPa}$ & $16 \mathrm{MPa}$ \\
\hline (1) & 0.2 & 56.67 & 21.16 & 8.29 & 5.50 & 3.48 & 4.14 \\
\hline (2) & 0.4 & 59.72 & 23.96 & 10.37 & 4.89 & 5.73 & 4.77 \\
\hline (3) & 0.6 & 63.40 & 27.08 & 12.83 & 7.52 & 7.55 & 6.35 \\
\hline$(4)$ & 0.8 & 67.16 & 30.15 & 15.67 & 8.75 & 9.09 & 6.14 \\
\hline
\end{tabular}

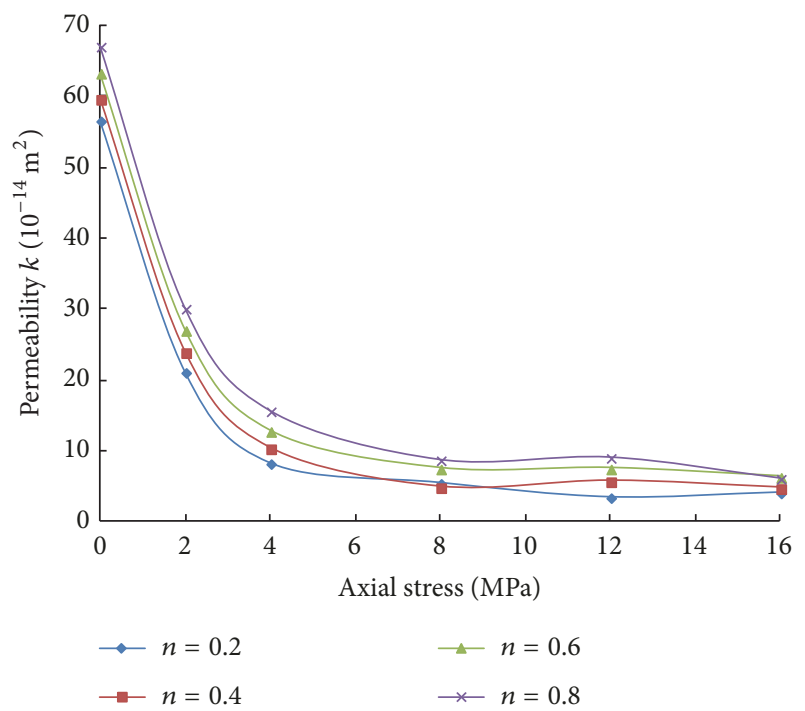

FIGURE 8: The decrease process of the permeability with the axial stress.

random and uncertain due to the particle crushing and particle rearrangement. As a result, the permeability shows some local fluctuation.

The permeability is influenced by the initial gradation. Under the same axial stress, a larger Talbot power exponent corresponds to a larger permeability. This is mainly because a larger Talbot power exponent corresponds to a greater mass percent of large particles. It is more likely to cause large capillary tubes for water flow, thus resulting in a larger permeability.

Figure 9 shows the permeability-fractal dimension curves. In Figure 9, it can be seen that the permeability decreases with an increase in the fractal dimension of the particle size distribution, and the relation between them can be described by an exponential function

$$
k=a_{2} e^{b_{2} D}+c_{2}
$$

where $k$ is the permeability, $D$ is the fractal dimension of the particle size distribution, and $a_{2}, b_{2}$, and $c_{2}$ are the regression coefficients.

In this study, the saturated crushed sandstone is taken as a research object. The results reveal the change rules of the pore structure, particle size distribution, porosity, and permeability with the increase of axial loading from $0 \mathrm{MPa}$ to $16 \mathrm{MPa}$. Both the X-ray Computed Tomography and

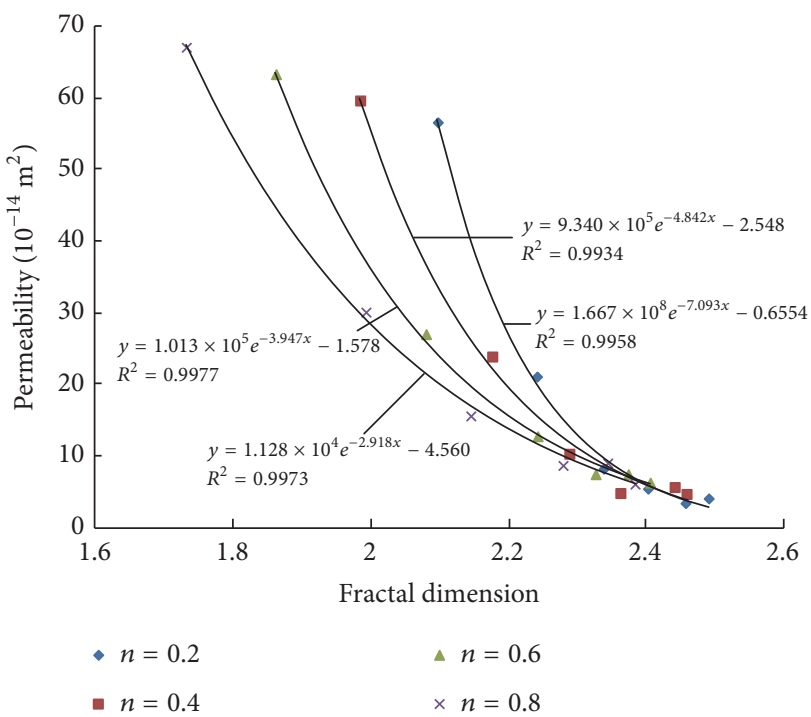

FIGURE 9: The exponential decline curves between the permeability and the fractal dimension.

experiment results show that $4 \mathrm{MPa}$ is a key axial stress value in affecting pore structure, particle size distribution, porosity, and permeability of the saturated crushed sandstone under compression. Actually, many factors such as rock properties, rock moisture content, and inner defects of rock may greatly influence the magnitude of the key axial stress. In future, a further study of the particle size distribution and permeability evolution for the rocks under different rock properties and other factors is necessary to be performed.

It is found that the fractal dimension of the particle size distribution is an effective method for describing the particle crushing state of saturated crushed sandstone under compression. However, the validity of the relationship between fractal dimension and porosity and permeability needs to be proved by theoretical analysis. Moreover, we cannot obtain a quantitative relationship between the pore structure evolution rule and the fractal dimension of the particle size distribution, which needs to be further studied.

\section{Conclusions}

(1) X-ray CT results reveal that when the axial stress increases from $0 \mathrm{MPa}$ to $4 \mathrm{MPa}$, a large amount of particle crushing occurs. The pore structure (including the contact mode between rock particles, the number 
TABLE 7: The values of parameters used to calculate the permeability.

(a) $n=0.2$

\begin{tabular}{|c|c|c|c|}
\hline $\begin{array}{l}\text { Axial stress } \\
(\mathrm{MPa})\end{array}$ & $\begin{array}{l}\text { Pore water pressure gradient } \\
(\mathrm{MPa} / \mathrm{m})\end{array}$ & $\begin{array}{l}\text { Water flow velocity } \\
\left(10^{-3} \mathrm{~m} / \mathrm{s}\right)\end{array}$ & $\begin{array}{c}\text { Permeability } \\
\left(10^{-14} \mathrm{~m}^{2}\right)\end{array}$ \\
\hline \multirow{4}{*}{0} & 5 & 4.43 & \multirow{4}{*}{56.67} \\
\hline & 10 & 5.59 & \\
\hline & 15 & 7.42 & \\
\hline & 20 & 12.31 & \\
\hline \multirow{4}{*}{2} & 5 & 1.42 & \multirow{4}{*}{21.16} \\
\hline & 10 & 1.91 & \\
\hline & 15 & 2.91 & \\
\hline & 20 & 4.21 & \\
\hline \multirow{4}{*}{4} & 5 & 0.57 & \multirow{4}{*}{8.29} \\
\hline & 10 & 0.79 & \\
\hline & 15 & 1.03 & \\
\hline & 20 & 1.60 & \\
\hline \multirow{4}{*}{8} & 5 & 0.39 & \multirow{4}{*}{5.50} \\
\hline & 10 & 0.47 & \\
\hline & 15 & 0.66 & \\
\hline & 20 & 0.99 & \\
\hline \multirow{4}{*}{12} & 5 & 0.27 & \multirow{4}{*}{3.48} \\
\hline & 10 & 0.35 & \\
\hline & 15 & 0.47 & \\
\hline & 20 & 0.78 & \\
\hline \multirow{4}{*}{16} & 5 & 0.26 & \multirow{4}{*}{4.14} \\
\hline & 10 & 0.39 & \\
\hline & 15 & 0.51 & \\
\hline & 20 & 0.76 & \\
\hline
\end{tabular}

(b) $n=0.4$

\begin{tabular}{|c|c|c|c|}
\hline $\begin{array}{l}\begin{array}{l}\text { Axial stress } \\
(\mathrm{MPa})\end{array} \\
\end{array}$ & $\begin{array}{l}\text { Pore water pressure gradient } \\
(\mathrm{MPa} / \mathrm{m})\end{array}$ & $\begin{array}{l}\text { Water flow velocity } \\
\left(10^{-3} \mathrm{~m} / \mathrm{s}\right)\end{array}$ & $\begin{array}{c}\text { Permeability } \\
\left(10^{-14} \mathrm{~m}^{2}\right)\end{array}$ \\
\hline \multirow{4}{*}{0} & 5 & 4.57 & \multirow{4}{*}{59.72} \\
\hline & 10 & 5.24 & \\
\hline & 15 & 7.29 & \\
\hline & 20 & 11.40 & \\
\hline \multirow{4}{*}{2} & 5 & 1.52 & \multirow{4}{*}{23.96} \\
\hline & 10 & 2.19 & \\
\hline & 15 & 2.87 & \\
\hline & 20 & 4.26 & \\
\hline \multirow{4}{*}{4} & 5 & 0.72 & \multirow{4}{*}{10.37} \\
\hline & 10 & 0.88 & \\
\hline & 15 & 1.64 & \\
\hline & 20 & 2.24 & \\
\hline \multirow{4}{*}{8} & 5 & 0.32 & \multirow{4}{*}{4.89} \\
\hline & 10 & 0.41 & \\
\hline & 15 & 0.63 & \\
\hline & 20 & 0.88 & \\
\hline
\end{tabular}


(b) Continued.

\begin{tabular}{|c|c|c|c|}
\hline $\begin{array}{l}\text { Axial stress } \\
(\mathrm{MPa}) \\
\end{array}$ & $\begin{array}{l}\text { Pore water pressure gradient } \\
(\mathrm{MPa} / \mathrm{m})\end{array}$ & $\begin{array}{l}\text { Water flow velocity } \\
\qquad\left(10^{-3} \mathrm{~m} / \mathrm{s}\right)\end{array}$ & $\begin{array}{l}\text { Permeability } \\
\left(10^{-14} \mathrm{~m}^{2}\right)\end{array}$ \\
\hline \multirow{4}{*}{12} & 5 & 0.36 & \multirow{4}{*}{5.73} \\
\hline & 10 & 0.49 & \\
\hline & 15 & 0.73 & \\
\hline & 20 & 1.02 & \\
\hline \multirow{4}{*}{16} & 5 & 0.32 & \multirow{4}{*}{4.77} \\
\hline & 10 & 0.43 & \\
\hline & 15 & 0.59 & \\
\hline & 20 & 0.88 & \\
\hline
\end{tabular}

(c) $n=0.6$

\begin{tabular}{|c|c|c|c|}
\hline $\begin{array}{l}\begin{array}{l}\text { Axial stress } \\
(\mathrm{MPa})\end{array} \\
\end{array}$ & $\begin{array}{l}\text { Pore water pressure gradient } \\
\qquad(\mathrm{MPa} / \mathrm{m})\end{array}$ & $\begin{array}{l}\text { Water flow velocity } \\
\left(10^{-3} \mathrm{~m} / \mathrm{s}\right)\end{array}$ & $\begin{array}{c}\text { Permeability } \\
\left(10^{-14} \mathrm{~m}^{2}\right)\end{array}$ \\
\hline \multirow{4}{*}{0} & 5 & 4.45 & \multirow{4}{*}{63.40} \\
\hline & 10 & 5.77 & \\
\hline & 15 & 8.12 & \\
\hline & 20 & 12.28 & \\
\hline \multirow{4}{*}{2} & 5 & 1.86 & \multirow{4}{*}{27.08} \\
\hline & 10 & 2.77 & \\
\hline & 15 & 3.39 & \\
\hline & 20 & 5.46 & \\
\hline \multirow{4}{*}{4} & 5 & 0.96 & \multirow{4}{*}{12.83} \\
\hline & 10 & 1.11 & \\
\hline & 15 & 1.56 & \\
\hline & 20 & 2.40 & \\
\hline \multirow{4}{*}{8} & 5 & 0.52 & \multirow{4}{*}{7.52} \\
\hline & 10 & 0.72 & \\
\hline & 15 & 0.91 & \\
\hline & 20 & 1.43 & \\
\hline \multirow{4}{*}{12} & 5 & 0.50 & \multirow{4}{*}{7.55} \\
\hline & 10 & 0.68 & \\
\hline & 15 & 0.99 & \\
\hline & 20 & 1.44 & \\
\hline \multirow{4}{*}{16} & 5 & 0.43 & \multirow{4}{*}{6.35} \\
\hline & 10 & 0.48 & \\
\hline & 15 & 0.65 & \\
\hline & 20 & 0.96 & \\
\hline
\end{tabular}

(d) $n=0.8$

\begin{tabular}{|c|c|c|c|}
\hline $\begin{array}{l}\text { Axial stress } \\
(\mathrm{MPa})\end{array}$ & $\begin{array}{l}\text { Pore water pressure gradient } \\
(\mathrm{MPa} / \mathrm{m})\end{array}$ & $\begin{array}{l}\text { Water flow velocity } \\
\qquad\left(10^{-3} \mathrm{~m} / \mathrm{s}\right)\end{array}$ & $\begin{array}{c}\text { Permeability } \\
\left(10^{-14} \mathrm{~m}^{2}\right)\end{array}$ \\
\hline \multirow{4}{*}{0} & 5 & 3.99 & \multirow{4}{*}{67.16} \\
\hline & 10 & 5.85 & \\
\hline & 15 & 8.40 & \\
\hline & 20 & 11.68 & \\
\hline \multirow{4}{*}{2} & 5 & 2.32 & \multirow{4}{*}{30.15} \\
\hline & 10 & 2.82 & \\
\hline & 15 & 4.01 & \\
\hline & 20 & 6.37 & \\
\hline
\end{tabular}


(d) Continued.

\begin{tabular}{|c|c|c|c|}
\hline $\begin{array}{l}\text { Axial stress } \\
(\mathrm{MPa})\end{array}$ & $\begin{array}{l}\text { Pore water pressure gradient } \\
(\mathrm{MPa} / \mathrm{m})\end{array}$ & $\begin{array}{l}\text { Water flow velocity } \\
\quad\left(10^{-3} \mathrm{~m} / \mathrm{s}\right)\end{array}$ & $\begin{array}{c}\text { Permeability } \\
\left(10^{-14} \mathrm{~m}^{2}\right)\end{array}$ \\
\hline \multirow{4}{*}{4} & 5 & 1.15 & \multirow{4}{*}{15.67} \\
\hline & 10 & 1.39 & \\
\hline & 15 & 1.93 & \\
\hline & 20 & 2.97 & \\
\hline \multirow{4}{*}{8} & 5 & 0.57 & \multirow{4}{*}{8.75} \\
\hline & 10 & 0.81 & \\
\hline & 15 & 1.12 & \\
\hline & 20 & 1.66 & \\
\hline \multirow{4}{*}{12} & 5 & 0.62 & \multirow{4}{*}{9.09} \\
\hline & 10 & 0.81 & \\
\hline & 15 & 1.15 & \\
\hline & 20 & 1.70 & \\
\hline \multirow{4}{*}{16} & 5 & 0.39 & \multirow{4}{*}{6.14} \\
\hline & 10 & 0.54 & \\
\hline & 15 & 0.71 & \\
\hline & 20 & 1.05 & \\
\hline
\end{tabular}

and size of pores, and the connectivity between pores) changes greatly.

(2) During compression, the particle size distribution satisfies the fractal condition well, and the fractal dimension of particle size distribution is an effective method for describing the particle crushing state of saturated crushed sandstone. The increased process consists of two stages that are a rapid increase $(0-4 \mathrm{MPa})$ and a slow increase (4-16 MPa). During the rapid increase stage, the fractal dimension of the particle size distribution increases rapidly by over $60 \%$ of the total increase $(0-16 \mathrm{MPa})$.

(3) The porosity decreases with an increase of the fractal dimension of the particle size distribution, and the relation between them can be described by a linear function.

(4) When the axial stress increases from $0 \mathrm{MPa}$ to $4 \mathrm{MPa}$, the permeability decreases sharply by about $85 \%$ of the total decrease. These results indicate that $4 \mathrm{MPa}$ is a key value in controlling the particle size distribution and the permeability of the saturated crushed sandstone under axial compression. The permeability is influenced by the initial gradation of the specimens, and a larger Talbot exponent corresponds to a larger permeability.

\section{Conflicts of Interest}

The authors declare that there are no conflicts of interest regarding the publication of this paper.

\section{Acknowledgments}

The authors acknowledge financial support by the Fundamental Research Funds for the Central Universities (2015XKZD06), the Priority Academic Program Development of Jiangsu Higher Education Institutions (PAPD), and the National Natural Science Foundation of China (51674247).

\section{References}

[1] X. Miao, S. Li, Z. Chen, and W. Liu, "Experimental Study of Seepage Properties of Broken Sandstone Under Different Porosities," Transport in Porous Media, vol. 86, no. 3, pp. 805814, 2011

[2] D. Ma, X. X. Miao, G. H. Jiang, H. B. Bai, and Z. Q. Chen, "An experimental investigation of permeability measurement of water flow in crushed rocks," Transport in Porous Media, vol. 105, no. 3, pp. 571-595, 2014.

[3] D. Ma, H. Bai, Z. Chen, and H. Pu, "Effect of particle mixture on seepage properties of crushed mudstones," Transport in Porous Media, vol. 108, no. 2, pp. 257-277, 2015.

[4] M. Takei, O. Kusakabe, and T. Hayashi, "Time-dependent behavior of crushable materials in one-dimensional compression tests," Soils and Foundations, vol. 41, no. 1, pp. 97-121, 2001.

[5] G. R. McDowell and J. J. Khan, "Creep of granular materials," Granular Matter, vol. 5, no. 3, pp. 115-120, 2003.

[6] S. L. Karner, J. S. Chester, F. M. Chester, A. K. Kronenberg, and A. Hajash Jr., "Laboratory deformation of granular quartz sand: Implications for the burial of clastic rocks," AAPG Bulletin, vol. 89, no. 5, pp. 603-625, 2005.

[7] R. H. Brzesowsky, S. J. T. Hangx, N. Brantut, and C. J. Spiers, "Compaction creep of sands due to time-dependent grain 
failure: Effects of chemical environment, applied stress, and grain size," Journal of Geophysical Research: Solid Earth, vol. 119, no. 10, pp. 7521-7541, 2014.

[8] Z. G. Ma, R. X. Gu, Z. M. Huang, P. Gong, L. Zhang, and D. Ma, "Experimental study on creep behavior of saturated disaggregated sandstone," International Journal of Rock Mechanics \& Mining Science, vol. 66, no. 1, pp. 76-83, 2014.

[9] Z. Zhao and E.-X. Song, "Particle mechanics modeling of creep behavior of rockfill materials under dry and wet conditions," Computers \& Geosciences, vol. 68, pp. 137-146, 2015.

[10] N. Miura and S. O-Hara, "Particle-crushing of a decomposed granite soil under shear stresses," Soils and Foundations, vol. 19, no. 3, pp. 1-14, 1979.

[11] B. O. Hardin, "Crushing of soil particles," Journal of Geotechnical Engineering, vol. 111, no. 10, pp. 1177-1192, 1985.

[12] B. B. Mandelbrot, The Fractal Geometry of Nature, Henry Holt and Company, San Francisco, Calif, USA, 1982.

[13] D. L. Turcotte, "Fractals and fragmentation," Journal of Geophysical Research: Solid Earth, vol. 91, no. 2, pp. 1921-1926, 1986.

[14] H. P. Xie and W. G. Pariseau, "Fractal character and mechanism of rock bursts," International Journal of Rock Mechanics and Mining Sciences \& Geomechanics Abstracts, vol. 30, no. 4, pp. 343-350, 1993.

[15] E. Perfect, "Fractal models for the fragmentation of rocks and soils: a review," Engineering Geology, vol. 48, no. 3-4, pp. 185198, 1997.

[16] M. Martínez-Mena, L. K. Deeks, and A. G. Williams, "An evaluation of a fragmentation fractal dimension technique to determine soil erodibility," Geoderma, vol. 90, no. 1-2, pp. 8798, 1999.

[17] K. Li and R. N. Horne, "Experimental study and fractal analysis of heterogeneity in naturally fractured rocks," Transport in Porous Media, vol. 78, no. 2, pp. 217-231, 2009.

[18] J.-Y. Xu and S. Liu, "Research on fractal characteristics of marble fragments subjected to impact loading," Yantu Lixue/Rock and Soil Mechanics, vol. 33, no. 11, pp. 3225-3229, 2012.

[19] L. Xiao, S. Xue, G. Liu, and C. Zhang, "Fractal features of soil profiles under different land use patterns on the Loess Plateau, China," Journal of Arid Land, vol. 6, no. 5, pp. 550-560, 2014.

[20] R. R. Filgueira, L. L. Fournier, C. I. Cerisola, P. Gelati, and M. G. García, "Particle-size distribution in soils: A critical study of the fractal model validation," Geoderma, vol. 134, no. 3-4, pp. 327-334, 2006.

[21] X. Liu, G. Zhang, G. C. Heathman, Y. Wang, and C.-H. Huang, "Fractal features of soil particle-size distribution as affected by plant communities in the forested region of Mountain Yimeng, China," Geoderma, vol. 154, no. 1-2, pp. 123-130, 2009.

[22] G. Xu, Z. Li, and P. Li, "Fractal features of soil particle-size distribution and total soil nitrogen distribution in a typical watershed in the source area of the middle Dan River, China," Catena, vol. 101, pp. 17-23, 2013.

[23] P. A. Witherspoon and J. E. Gale, "Mechanical and hydraulic properties of rocks related to induced seismicity, Engineering Geology, vol. 11, no. 1, pp. 23-55, 1977.

[24] M. D. Zoback and J. D. Byerlee, "Note on the deformational behavior and permeability of crushed granite," International Journal of Rock Mechanics and Mining Science \&amp; Geomechanics Abstracts, vol. 13, no. 10, pp. 291-294, 1976.

[25] J. Legrand, "Revisited analysis of pressure drop in flow through crushed rocks," Journal of Hydraulic Engineering, vol. 128, no. 11, pp. 1027-1031, 2002.
[26] I. Engelhardt and S. Finsterle, “Thermal-hydraulic experiments with bentonite/crushed rock mixtures and estimation of effective parameters by inverse modeling," Applied Clay Science, vol. 23, no. 1-4, pp. 111-120, 2003.

[27] M. E. French, F. M. Chester, J. S. Chester, and J. E. Wilson, "Stress-dependent transport properties of fractured arkosic sandstone," Geofluids, vol. 16, no. 3, pp. 533-551, 2016.

[28] A. Rotevatn, T. H. Sandve, E. Keilegavlen, D. Kolyukhin, and H. Fossen, "Deformation bands and their impact on fluid flow in sandstone reservoirs: The role of natural thickness variations," Geofluids, vol. 13, no. 3, pp. 359-371, 2013.

[29] A. N. Talbot and F. E. Richart, "The strength of concrete, its relation to the cement aggregates and water," Illinois University English Express Station Bulletin, vol. 137, pp. 1-116, 1923.

[30] S. W. Tyler and S. W. Wheatcraft, "Fractal scaling of soil particlesize distributions: analysis and limitations," Soil Science Society of America Journal, vol. 56, no. 2, pp. 362-369, 1992.

[31] M., "Hydraulik - Von Philipp Forchheimer. X+566 S. B. G. Teubner, Leipzig-Berlin, 1914. Preis M. 18.-," Monatshefte für Mathematik und Physik, vol. 27, no. 1, p. A12, 1916. 

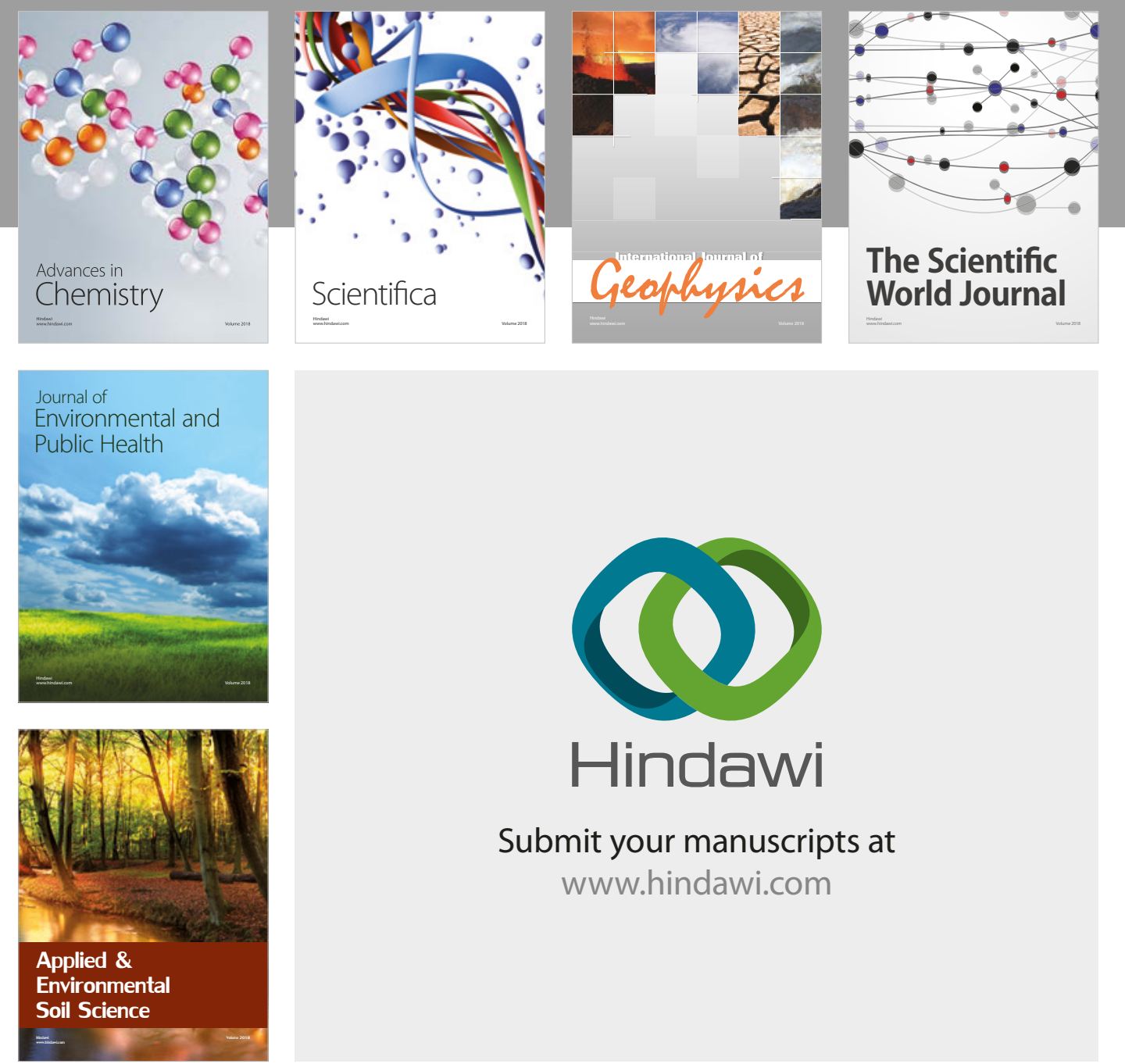

The Scientific

\section{World Journal}
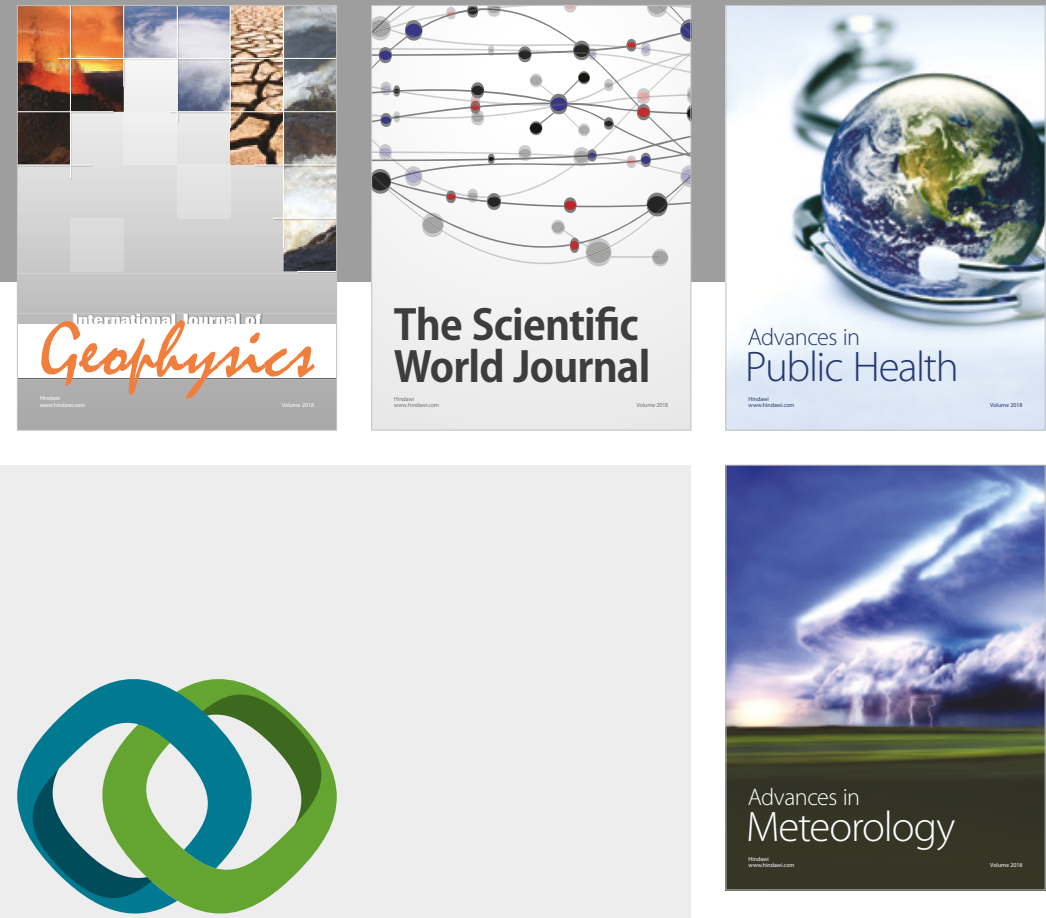

Advan

Public Health

\section{Hindawi}

Submit your manuscripts at

www.hindawi.com
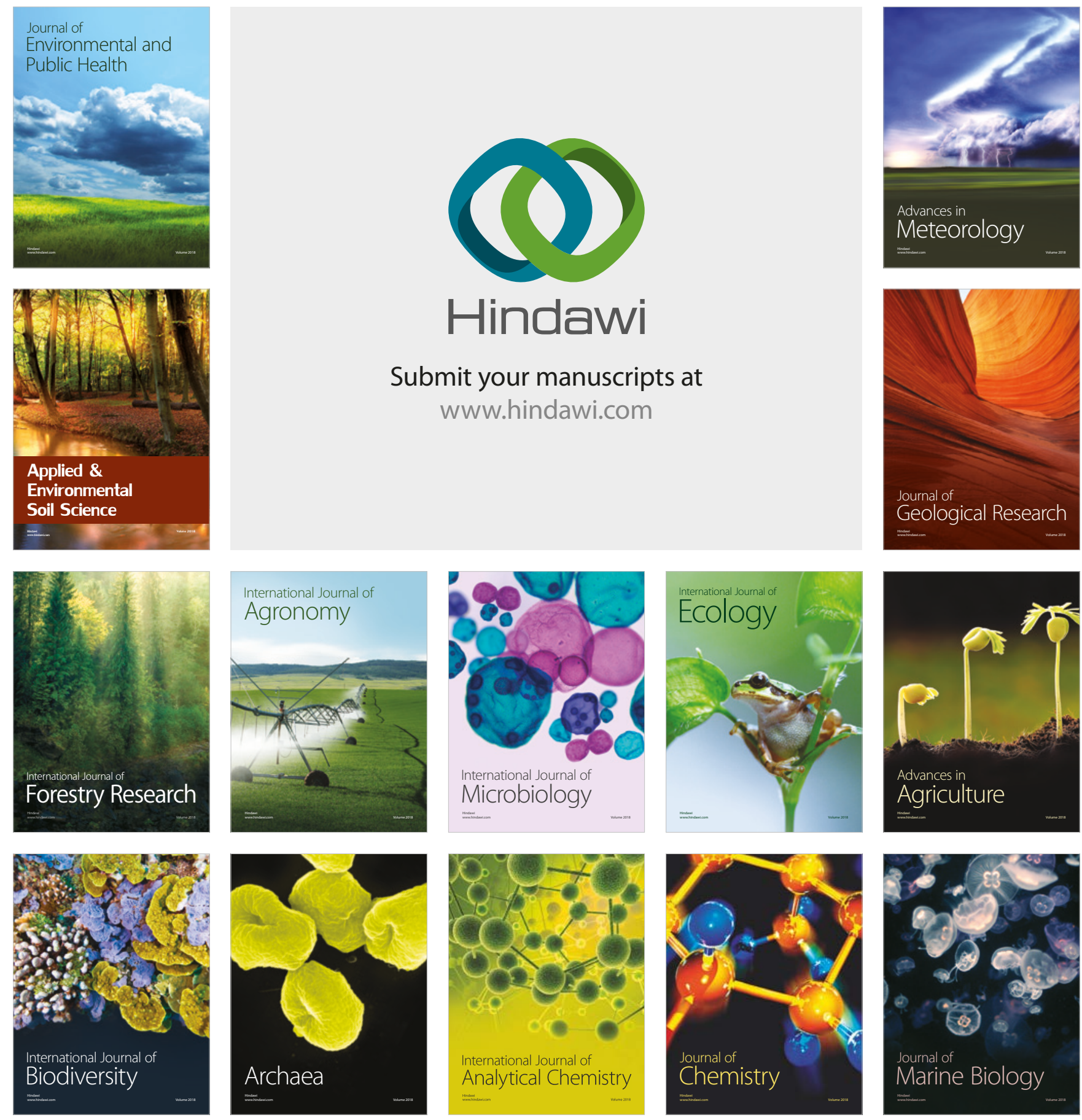